\section{International Mindedness: A Revised Conceptual Framework}

\author{
Akın Metli \\ Bilkent Erzurum Laboratory School (BELS), Turkey
}

\section{Jennie F. Lane}

İhsan Doğramacı Bilkent University, Turkey
Journal of Research in International Education 2020, Vol. 19(3) 202-219

(C) The Author(s) 2020

Article reuse guidelines: sagepub.com/journals-permissions DOI: I0.1 I 177//475240920976229 journals.sagepub.com/home/jri

\begin{abstract}
This paper suggests a revised framework for explaining, developing and assessing international mindedness (IM). A review of the literature - that presents initiatives, challenges, and debates regarding IM - concludes with an overview of selected conceptual frameworks that have been used to develop a shared understanding of IM. When the authors applied one of these frameworks in a previous empirical study, they found during data analysis that some aspects of the framework's key pillars played a more supportive role and that other components of IM needed further identification. As a result, this paper proposes a revision of the framework that features intercultural competence and global engagement, and identifies more specific components of these attributes, namely knowledge, skills, dispositions, and agency. The paper includes another review of the literature to emphasise how these components are important for the development, implementation, and assessment of international mindedness.
\end{abstract}

\title{
Keywords
}

agency, dispositions, framework, international mindedness

\section{Introduction}

The world we live in is increasingly interconnected, globalized and multicultural; as a result, there are more opportunities for people of today's world to communicate easily with those from different cultures and traditions. To ensure these interactions are meaningful, positive, and constructive, it has become necessary for world citizens to be lifelong learners who continually examine what they know, think, and feel about the global society. This global empathy, awareness, and understanding - what could be described as international mindedness (IM) - is a goal of many international education programs (Hill, 2012a; Hill, 2012b). 
Many researchers and educators have promoted and analyzed international mindedness (see, for instance, Bailey and Harwood, 2013; Barratt Hacking et al, 2017; Castro et al, 2013; Harwood and Bailey, 2012; Hayden and Thompson, 2013; Singh and Qi, 2013; Sriprakash et al, 2014). While they may agree on the philosophy of the concept, however, they often differ on an exact definition. Meanwhile, Marshall (2007) points out that educators may have comparable definitions of the concept, but use a title different than IM (such as global awareness). Since there is no universal single agreed definition of international mindedness (Hayden and Thompson, 2013), schools may find it difficult to interpret what it means, which in turn compromises their ability to teach and assess it. Furthermore, until recently there has not been a curricular framework or assessment tool to evaluate the effectiveness of how international mindedness is implemented within a school setting.

This paper explores the possibility of producing a revised version of the framework of international mindedness developed by Singh and Qi (2013). We initially review the literature on international mindedness in terms of its definitions, empirical research, suggestions for implementation and assessment. Included in this review is consideration of frameworks that have been used to define and assess international mindedness, including that presented by Singh and Qi. This framework was used in a previous study conducted by Metli, Martin and Lane (2019) to investigate international mindedness in two schools. The original purpose of the previous study was not to revise the framework; this grew out of the investigation during the data analysis. Information about this prior study and its role in creating the revised framework is provided in the methods section below. The revised framework, presented in the findings section, may serve as a guide for developing students' international mindedness and may be used to develop assessment tools or rubrics to assess students' international mindedness as they progress through their journey in international education. In particular, review of the literature supports how aspects of the revised framework help to ensure that important cognitive, socio-emotional, and behavioral components of IM are considered when developing intercultural competence and providing opportunities for global engagement.

\section{Literature Review}

\section{International mindedness}

Reference to intercultural understanding and taking action to address global problems is common in the definitions of international mindedness found in literature. To exemplify, Harwood and Bailey (2012: 3) define international mindedness as "a person's capacity to transcend the limits of a worldview informed by a single experience of nationality, creed, culture or philosophy and recognize in the richness of diversity a multiplicity of ways of engaging with the world". They further explain that internationally minded people have the necessary understanding and actions for both national and international citizenship. Ranger (2013) asserts that internationally minded individuals' values can be observed through their actions since they show more than an understanding of internationalism. They are open-minded about common humanity and respect each other's cultures and beliefs. They also take action through discussion and collaboration to help build a better and more peaceful world. Another definition of international mindedness based on a similar understanding suggests that international mindedness refers to an openness to and curiosity about the world and people of other cultures, and a striving toward a profound level of understanding of the complexity and diversity of human interactions (Castro et al, 2013).

It may seem that a common understanding of international mindedness exists because of these shared terms; however, conceptual disagreements may still arise because similar terms and terminology are used to refer to international mindedness. Marshall (2007) points out that teachers and 
global educationalists encounter similar terms regarding global citizenship terminology. Terms such as world-mindedness education, global citizenship education, international education, education with a global or international dimension, world studies and education for international understanding appear to be similar. However, their distinctiveness and relationships are not always clear.

One organisation that has taken notable steps to define IM is the International Baccalaureate (IB). According to the philosophy of the IB, the aim of its four programs (Diploma Programme, Career-related Programme, Middle Years Programme, Primary Years Programme) is "to develop internationally minded people who, recognizing their common humanity and shared guardianship of the planet, help to create a better and more peaceful world" (IB, 2008a: 5). The IB definition of international mindedness, largely associated with global/intercultural understanding, is considered as an open attitude for curiosity to gain an understanding of different cultures and interactions, as the IB mission statement emphasizes "intercultural understanding and respect" (IB, 2008a).

Despite such efforts to define IM, schools that offer IB programmes may still find international mindedness difficult to interpret (Hayden and Thompson, 2013) because interpretation may differ according to context. Furthermore, it should be noted that such definitions and international programs including the IB may be criticised by some for promoting western ways of thinking (see, for instance, Sriprakash et al, 2014; Tamatea, 2008; Wright and Buchanan, 2017). Poonoosamy (2010: 19), for example, remarks that overarching aspirations of international mindedness "may still be decided by the western knowledge industry". Despite these challenges and critiques, or perhaps because of them, researchers continue to explore ways of defining and further investigating international mindedness. A number of these studies are reviewed below.

\section{Selected research related to international mindedness}

Experts in the field of international education recommend strategies that support the development of international mindedness. Schools that embrace a global approach to education may include international mindedness in their mission, vision and philosophy (Ranger, 2013; Swetz and Swetz, 2014). International mindedness may be promoted effectively when it is interwoven in the standards, curriculum, ethos and commitment of the school. Thus, there needs to be an explicit and purposeful pedagogy in schools for developing students' global engagement (Wasner, 2016). Such a commitment will help schools to develop internationally minded students who seek peace, and have enthusiasm for global cooperation through school activities in order to act on global issues (Skelton et al, 2002). According to this view, international mindedness should be an integral part of the school's climate, standards, curriculum, extra-curriculum, instruction and assessment in preparing students for an interdependent world (Skelton et al, 2002). International schools may seem naturally primed to develop international mindedness since many have diverse student populations. Some researchers caution, however, that immersion in a culturally diverse environment does not necessarily lead to greater respect, tolerance and understanding. Jackson (2015) found that 'education abroad' students did not benefit from their stay in the host environment and experienced few if any gains in intercultural sensitivity. Metli, Martin and Lane (2019) have argued that the development of international mindedness in schools cannot be taken for granted. Similarly, Cause (2009) points out that teachers need to understand that international mindedness will not be developed simply by putting children of different nationalities in the same classroom. Cause further argues that such a melting-pot approach may contribute to, but by itself will not develop, internationally minded students. Nevertheless, there is some value in students of diverse cultures studying together. Belal (2017: 31 ), for instance, proposed that "developing a wider worldview and international mindedness can at least partly be attributed to having a diverse student body". 
Clearly, a deeper understanding is needed of what contributes to the development of international mindedness, as an under-studied aspect of schooling in international education (Wright and Buchanan, 2017). Savva and Stanfield (2018) note that although international mindedness is promoted as a concept that centers on the principles of morality and character, there is little to be found about international mindedness in the fields of moral development and character education. Research studies undertaken to date appear to focus more on the documentation, reflection and conceptualization of international mindedness (Bailey and Harwood, 2013; Castro et al, 2013; Harwood and Bailey, 2012; Singh and Qi, 2013; Sriprakash et al, 2014).

A number of empirical studies on the development and implementation of practicing international mindedness may be found in the literature. The empirical piece of research conducted by Sriprakash et al (2014) is a cross-cultural qualitative comparative study of international mindedness. Through interviews with parents, teachers and students at six schools, the study offers comparative insights into the concept of international mindedness across cultures. The aim of the research was to provide a resource for the wider IB community of empirically-based concepts and practices of international mindedness that have emerged from the experiences and perspectives of students, parents and teachers in IB schools. According to the findings of this study, international mindedness has varied manifestations. It can be seen as a tool for global mobility, a form of western cultural capital, and a strategy for academic advancement. Schools are places where the conceptualization and implementation of international mindedness is facilitated through historical, social and political contexts. The practices of international mindedness varied across the school contexts in this study and were dependent on school cultures, level of commitment from teachers and leadership teams, and extent of integration and promotion across school activities. Successful school practices of international mindedness, argue the authors, include embodying international mindedness into their long-term strategies, active leadership to drive school planning and practice of international mindedness, explicitly linking school events to ideas relating to international mindedness, and engaging the critical and creative capacity of students to plan and organize events for international mindedness.

More recently, Saavedra (2016) investigated IB Diploma Programme (IBDP) students' "civic mindedness" and "model citizenship" through surveys and interviews at four public schools in the USA. She found that the IB Diploma Programme helped students to develop their civic mindedness through being actively engaged in political, social, local and global issues. Another study by Wright and Buchanan (2017) explored narratives of 22 former IBDP students, aged 20 to 63, reflecting on their school experiences. Drawing on the life story approach, the study utilized a semi-structured interview method to elicit biographical accounts of former graduates' reflections on their development of international mindedness. One important finding of the study related to the type of school (national or international school) from which the former IB students had graduated. Those who graduated from international schools recalled a school ethos specifically promoting international mindedness and had vivid reflections on their experiences of participating in intercultural activities.

A more recent empirical study by Barratt Hacking et al (2017) investigated the promising practices of development and assessment of international mindedness. The findings of their study revealed how schools can nurture IM through their standards, curriculum and commitment. The study explored how IB schools conceptualize, implement and assess international mindedness and understand related challenges. Researchers investigated promising practices in developing and assessing international mindedness at two pilot schools and nine case study schools with different programs and contextual locations, in order to gain insight into perspectives at each school. Their findings suggest that intentional practices promote IM, since the case study schools were actively working to develop students' IM. School communities were therefore 
recommended to discuss, define, develop, assess and evaluate IM according to their particular contexts and profiles.

However, it should not be assumed that international mindedness necessarily develops to a greater extent at an international school than it does at a national school. Beek (2017) compared IBDP students' international mindedness in a national school and an international school in the Czech Republic. Statistical analysis of the results revealed no significant difference between students from the two participating schools. Similarly, the study by Metli (2018) compared national school students to international school students in terms of their development of international mindedness. As with Beek's findings, there was no statistically significant difference between students enrolled in the national school and international school in terms of their levels of intercultural understanding and global engagement. It would appear to be important, therefore, that schools - whether their student body is intercultural or monocultural - continually monitor and assess their efforts to promote international mindedness.

\section{Implementing and assessing international mindedness}

Many schools that might view themselves as internationally minded face the challenge of providing evidence that they are indeed an internationally minded institution (Bunnell, 2019). For that reason, consideration has to be given to how to assess international mindedness. Harwood and Bailey (2012) note that surveys provide opportunities for self-reflection on students' evidence collected in a portfolio or self-reflective journal (such as video and audio recordings, letters and emails, essays, photographs, plays, poems, personal statements and evidence of participation in school and local activities). However, Koester and Lustig (2015) caution that self-reports on their own do not provide adequate assessment of intercultural competence. Harwood (in Haywood, 2019) also notes that "it may well be impossible to develop an overarching system of assessment", while adding that there are still benefits to evaluating the progression of international mindedness if only in key areas such as language, culture, human society, global issues and world views.

Given the definitional challenges of IM, it is not surprising that challenges also arise when it comes to its assessment. Some strategies such as interviews, while insightful, may be too subjective and limited by misperceptions (Tarc and Beatty, 2012). At the other extreme, quantitative assessments, such as examinations, may not reflect the depth and breadth of all aspects of IM. Furthermore, too much emphasis on examination results can affect teaching styles and cause schools to move from a constructivist or social-constructivist approach to a more behaviorist methodology (Lineham, 2013). This may have a negative effect on student learning and the possibility of a curriculum promoting the aims of international education. Therefore, there is still need for clearer understanding about how to assess, or even describe, the extent to which students appreciate and embrace the international mindedness values promoted by the IB in the IB Learner Profile (Wells, 2011): ten attributes that it is intended should be developed by all students of IB programmes (IB, 2008a).

Such assessment tools would not necessarily be used only for monitoring students' development of international mindedness. School leaders and teachers, it is argued, must also strive to be internationally minded, being "institutionally and personally self-reflexive, critically minded - cognizant of power dynamics and micropolitics - interculturally aware" (Tarc, 2018: 425-426). To this effect, Macpherson (2017) used the Global Competence Aptitude Assessment (GCAA) to assess IM with multicultural and multilingual staff of an IB Primary Years Programme (IB PYP) school in Northern Iraq. She found a statistically significant difference in international mindedness between two groups of staff members: those from Iraq and surrounding countries (Turkey, Greece, and Azerbaijan) showed lower levels of IM than did those from Western countries. Thus, 
she proposed that the teachers' and administrators' reflections on the GCAA could be used for developing an induction program and professional development program for the faculty that would foster IM. Habib (2018) meanwhile conducted a qualitative study through in-depth individual interviews in order to explore understanding of international mindedness in higher education faculty members in Pakistan. Habib's study revealed that faculty members had a limited understanding of international mindedness, applied it minimally in their teaching practices and needed more professional development to promote global citizenship. The need for professional development for teachers was also discussed in Baily and Holmarsdottir's (2019: 241) study which points out that "the lack of agency for teachers to be real change agents requires that teachers are supported on a professional level" for promoting international mindedness.

The above studies illustrate that understandings of and strategies to develop and assess international mindedness are still being undertaken and critiqued. These discussions in the literature continue to seek common terms and specific aspects for international mindedness and are part of the process of developing mutual understanding (Fannon, 2013; Harwood and Bailey, 2012). One strategy researchers have used to develop a shared understanding of international mindedness is the design of a framework. The following section includes an overview of several such frameworks, concluding with a proposed revision of one of them.

\section{Conceptual frameworks for international mindedness}

In their international mindedness framework, Vooren and Lindsey (2012) stress the importance of attitudes and values (dispositions), indicating that these are inherent in the IB Learner Profile. They advocate for these frameworks to be applied in schools throughout the world and not only international schools. Their framework includes cultural proficiency, with reference to the work of Lindsey et al (2005). Vooren and Lindsey explain that cultural proficiency includes appreciating and adjusting to diversity, handling conflict, and reflecting on and integrating cultural knowledge.

In their research, Harwood and Bailey (2012) provided a broad conceptual framework for the purpose of monitoring, assessing and laying a foundation for a shared understanding of international mindedness. The framework, entitled "Me and My World", covers five areas: world views, global issues, language, culture, and human society. Each area has certain aspects for which schools or individual students should collect evidence in their development of international mindedness. Within each area, students' experiences are monitored at four different levels of involvement: me, my school, my country and the world. This conceptualisation aims to enable schools to capture key features of international mindedness and to help schools to evaluate and monitor their progress and development for self-evaluation and for school improvement. Harwood and Bailey (2012) are aware of the fact that the conceptualization and assessment of international mindedness is an ongoing process in international education; they thus invite researchers to collaborate in contributing to the development of the IM framework by revising it through the addition of new aspects, areas and strands to the framework, adding different types of evidence for monitoring students' development of international mindedness.

Another example of a framework related to international mindedness is presented by Blackmore (2016). This recent pedagogical framework, based on critical review of literature, was developed for researching and evaluating global citizenship education in the teaching and learning process. It comprises four dimensions: critical thinking, dialogue, reflection, and responsible being/action. In the graphic depiction of the framework, dialogue is central to critical thinking and reflection; all three feed into responsible being/action. Aspects of this framework are comparable to that presented in the current study. For example, agency has ties to responsibility and action. In 
her discussion Blackmore refers to "action competence", which she explains is "about providing [students] with information and encouraging them to find appropriate solutions" ( $p$ 45). She emphasizes the quality of transformation in this dimension as it involves the process of removing oppression and allowing for expression. The skills and dispositions included in the present study's proposed revised framework for IM involve the dimensions of critical thinking, reflection, and dialogue. According to Blackmore, all these dimensions involve considering the "other" and critiquing the "self". She encourages teachers to use her framework in order to monitor the learning processes of students and to provide supportive guidelines as they become global citizens.

The IB-commissioned study on the conceptualization of IM and identification of existing instruments for assessing it, developed by Singh and Qi (2013), makes an attempt to clarify and define the concept of IM. Based on a systematic analysis of official IB documents about international mindedness, and a comprehensive literature review of international mindedness and other related constructs, the report from the study indicates that in IB documents international mindedness is explicitly manifested in what are described as the three pillars of IM: multilingualism, intercultural understanding and global engagement:

- Multilingualism means speaking more than two languages. It is based on the idea that languages help individuals to develop an appreciation of intercultural perspectives through connecting with people's histories and experiences (Castro et al, 2013).

- Intercultural understanding involves recognizing and reflecting on one's own perspective, as well as on the perspectives of others. Someone who has intercultural understanding explores human commonality, diversity and interconnection (Castro et al, 2013).

- Global engagement represents a commitment to addressing humanity's greatest challenges in the classroom and beyond. Students and teachers are encouraged to explore global and local issues, including developmentally appropriate aspects of the environment, development, conflicts, rights and cooperation and governance. Globally engaged people critically consider power and privilege, and recognize that they hold the earth and its resources in trust for future generations (Castro et al, 2013).

In their report, Singh and Qi (2013: 16) state that "intercultural understanding is still central to the IB understanding of international mindedness, while global engagement and multilingualism are pathways to the core element of intercultural understanding". According to Singh and Qi, critical language awareness can enhance intercultural awareness. Since understanding and respect are the core values that need to be developed for "a better and more peaceful world", the IB's conceptual framework for defining IM now incorporates intercultural understanding, global engagement and multilingualism. Intercultural understanding is argued to be necessary for international understanding and cooperation, which leads to responsibility for taking action to be globally engaged in addressing humanity's greatest challenges and thus international mindedness. Using this framework, Singh and Qi (2013) identified a variety of instruments that have been used in assessing IM, including the following:

- The Global-Mindedness Scale (GMS) measures levels of global mindedness in students studying in countries other than their home countries. The GMS identifies attitudes, beliefs, and behaviors related to global mindedness. It has five domains: responsibility, cultural pluralism, efficacy, global centrism, and interconnectedness (Hansen, 2010: 22-23, as cited by Singh and Qi, 2013).

- The Global Perspective Inventory (GPI) measures an individual's global perspective comprehensively (Merrill et al, 2012: 356, as cited by Singh and Qi, 2013). The instrument 
includes six scales_-both development and acquisition scales within each of three domains: Cognitive, Intrapersonal, and Interpersonal.

- The Global Competence Aptitude Assessment (GCAA) instrument measures knowledge, skills, and attitudes argued to be necessary for an individual to become globally competent. It assesses both Internal Readiness (personal traits and aptitude) and External Readiness (knowledge, skills and experiences) (Global Leadership Excellence, nd: 2, as cited by Singh and Qi, 2013).

- The Global Citizenship Scale (GCS) measures social responsibility, global competence, global civic engagement, and their sub-dimensions. Based on validity tests, global competence and global civic engagement are argued to be strong dimensions of global citizenship. However, social responsibility proved to be an unclear dimension. Yet the scale is theoretically grounded and empirically validated (Morais and Ogden, 2010, as cited by Singh and Qi, 2013).

- The Intercultural Development Inventory (IDI) measures orientations towards cultural differences, based on the Developmental Model of Intercultural Sensitivity (DMIS) developed by Bennett (1986). The DMIS consists of five stages on an intercultural development continuum, with Denial, Defense and Minimization described as relating to the ethnocentric mindset and Acceptance, Adaptation as the intercultural mindset.

Singh and Qi (2013) concluded that there is a need for a combination of measuring instruments to account for multiple competencies inherent in international mindedness and for the optimal assessment of international mindedness.

The next section describes a study that followed the recommendations of Singh and Qi arising from their own study. As will be seen, this study resulted in the revised framework presented in the current paper, and was designed to provide further insights into issues discussed in the preceding literature review: namely, that the definition of IM is still being debated and explored; more specifically, a closer exploration is needed of what is involved in IM development.

\section{The Study}

The current study proposes a revised framework that may be used as a guide for defining, monitoring and assessing international mindedness. Its creation arose from research conducted by the lead author and is described by Metli, Martin and Lane (2019), where Metli (2018) explored perceptions of forms of support for and challenges to international mindedness. Lane, the second author of the current paper, served along with Martin as consultants for Metli's study. Through qualitative and quantitative measures, Metli gathered perceptions from students, teachers, and administrators in two case study schools. One school had a predominantly international staff and student body, while the other was populated mainly by Turkish nationals. To analyse the data, he used the conceptual framework on international mindedness developed by Singh and Qi (2013).

As described above, the framework of Singh and Qi comprises the pillars of global engagement, intercultural understanding, and multilingualism. Following the recommendations of Singh and Qi (2013) for the optimal assessment of international mindedness, Metli (2018) identified a combination of instruments that addressed each of the pillars. For global engagement, participants completed the Global Citizenship Scale (GCS; Morais and Ogden, 2010) and for intercultural understanding they provided responses to the Intercultural Development Inventory (IDI; Hammer et al, 2003). In the literature, both scales are frequently described as having been implemented to successfully assess their respective attributes of international mindedness. 
It was more challenging, however, to find an established instrument that could be used to assess multilingualism. The concept of multilingualism for international mindedness, as discussed in the literature review of Singh and Qi, relates not only to speaking multiple languages. In other words, simply testing students' foreign language proficiency would provide an inadequate indication of their levels of multilingualism. On the other hand, the wide range of interpretations of the meaning of multilingualism made effective assessment challenging. Therefore, when Metli (2018) conducted his study, he focused not only on the proficiencies and varieties of the foreign language experiences of the participants through demographic surveys, but also on how the Diploma Programme core components help them to develop their ways of thinking and linguistic awareness in order to gain insights into the role of multilingualism and international mindedness (Metli, Martin and Lane, 2019).

Thematic content analysis was used for the qualitative analysis portion of Metli's (2018) study. Common themes and differences across stakeholders were qualitatively analysed with a scheme of work based on common themes arising from the interview and focus group transcripts, as well as from notes taken during school tour observations. While multilingualism was mainly analysed through a demographic survey due to the lack of an instrument that could be used with confidence to measure students' multilingualism, global engagement (GCS) and intercultural understanding (IDI) levels were quantitatively analysed based on descriptive statistics (means and standard deviations) and inferential statistics (paired sample $t$-tests and one way ANOVA with repeated measures) for school comparisons. The quantitative results revealed that no matter what type of school students came from: national vs international; continuum vs non-continuum (ie whether or not they offered all IB programmes in a cross-age-group continuum), there was statistically no significant difference in their development of intercultural understanding and global engagement in one year during their study of the IBDP. Detailed quantitative results of the research are reported in Metli, Martin and Lane (2019). The quantitative analysis was, however, less important a contributor to the development of a revised framework for IM than the analysis of qualitative data (discussed below) that led to recognition of the need for a revised framework.

\section{Methods used to develop the revised conceptual framework}

The pillars of IM outlined by Singh and Qi guided the researchers to deductively analyse the data by looking in the case study schools for examples of global engagement, intercultural understanding, and multilingualism (Hsieh and Shannon, 2005; Mayring, 2014). Protocols for interviews and focus groups were designed with the qualitative data analysis and areas of investigation in mind, using the following categories:

- Perceived meanings of IM

- Aims and objectives of DP core components

- Aspects of international mindedness and the IB mission

- Support for students relating to IM

- Evaluation that may relate to IM

- Perceived impact of DP on IM

- Support for teachers in the development of IM

As examples were identified, we also sought to explain how they contributed to IM. We noted that data in two of the pillars (intercultural understanding and global engagement) were more insightful about IM than data related to multilingualism. Furthermore, some findings from the data did not comply with any of the pillars; we needed to identify more specific components to better relate them to the pillars. When our findings were reviewed, we realized the outcomes of this analysis 


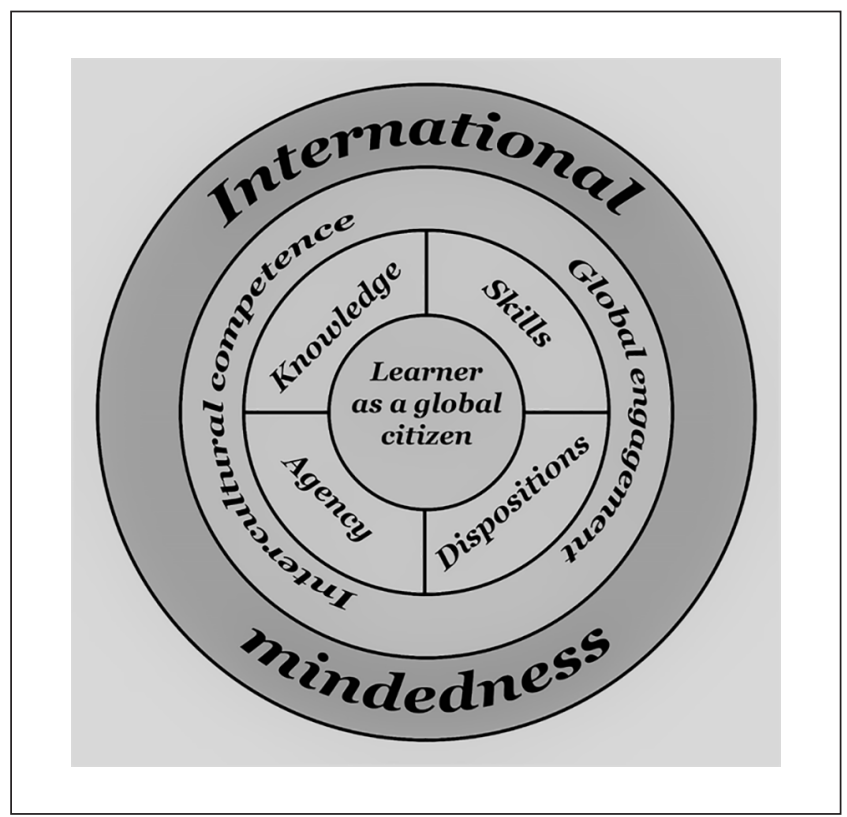

Figure I. A revised framework for international mindedness.

could benefit other researchers and educators who seek to develop and assess IM. Therefore, a revised framework was developed with our updated attributes and components. The revised framework is presented below, along with a review of literature that provides theoretical support for the new components.

\section{Findings}

\section{A revised framework for international mindedness}

Figure 1 shows a framework for IM. The following discussion explains how this framework is a development and revision of the pillars of IM presented by Singh and Qi (2013).

With this development, two key attributes of international mindedness are featured predominantly and further components of these attributes are identified. One of the main alterations to the original framework is that multilingualism is removed as a core or stand-alone pillar. As discussed below, language is still important in the development of international mindedness. However, the revised model allows it to be recognized as a skill that is supportive of intercultural competence (revised from intercultural understanding in the framework of Singh and Qi). The remaining two pillars, or attributes, are now reconfigured to be a ring of support that surrounds the concept of a learner becoming a global citizen. The development of international mindedness depends on intercultural competence and global engagement. Both of these attributes are further explained by the development of components, namely students' knowledge, skills, dispositions, and agency.

Intercultural competence. The following discussion will focus on aspects of the revised framework, especially those that may differ from earlier versions. The attribute of global engagement is retained in the current version. As noted by other scholars of international mindedness, the term intercultural competence may be a more comprehensive label for this attribute. For one thing, the term 
intercultural understanding leaves unclear whether it requires a particular skill or competency, and the importance of self-efficacy is not conveyed. In other words, understanding does not necessarily denote action and it may be possible to develop intercultural understanding without skills. A stronger and clearer word might be competence. Intercultural competence which includes knowledge, skills and attitudes is defined by Castro et al (2015: 192) as follows:

Intercultural competence . . f focuses on five savoirs (where the term savoir incorporates in English both knowledge and skills): savoir comprendre (skills of interpreting and relating), savoir faire (skills of discovery and interaction), savoir (knowledge), savoir être (attitudes) and savoir s'engager (critical cultural awareness). Intercultural competence, therefore, does not only describe a state of mind or a range of knowledge but also describes how such knowledge, skills and attitudes might be embodied within an intercultural person or a person acting interculturally.

Using the term intercultural competence in the revised conceptual framework of IM better emphasizes the IB's expectations regarding students' knowledge, skills, agency and dispositions. In past studies, intercultural understanding has been used synonymously with IM (Singh and Qi, 2013). However, more recent studies, especially those relating to the IB, recognize that in addition to competence, individuals need the opportunity to be engaged in global issues. Intercultural competence can be promoted through pedagogy, curriculum, and extra-curricular activities (Metli, Martin and Lane, 2019). Therefore, in this revised framework, IM encompasses intercultural competence and global engagement.

Multilingualism subsumed. Removing multilingualism as a pillar does not mean it is removed from the framework. We appreciate the arguments made by Singh and Qi and others that multilingualism is about more than speaking another language; nevertheless, the term can connote polyglotism. As students have various opportunities and skills in learning another language, the inclusion of multilingualism as one of the main pillars of IM may not be helpful in determining students' levels of IM development since it is possible for individuals to exhibit international mindedness even though they do not speak a foreign language proficiently. Alternatively, a person may have a penchant for learning different languages, yet remain ignorant of the associated cultures and ethnic attributes. That said, the IB does recognize that language learning is "integral to exploring and sustaining personal growth and cultural identity" (IB, 2008b: 25). Singh and Qi (2013) support this view and propose that multilingualism is a resource for engendering international mindedness, as critical language awareness entails intercultural awareness and thereby promotes international mindedness. Similarly, Barratt Hacking et al (2017: 64) found that "through learning and understanding how a language works, learners were thought to gain insight into other cultures and ways of thinking". To acknowledge, therefore, that learning a different language may support international mindedness, in the revised framework it is subsumed under intercultural competence, along with other attributes such as sensitivity, responsible behaviors, and supportive dispositions.

Examining the relationship between intercultural competence (formerly understanding) and global engagement provides further insight into the rationale for removing multilingualism as a pillar. In contrast to Singh and Qi's (2013) IM framework, where multilingualism and global engagement promote intercultural understanding, one of the outcomes of the study described by Metli, Martin and Lane (2019) suggests that intercultural competence and global engagement may mutually enhance and promote one another in the pursuit of international mindedness.

As Figure 2 indicates, multilingualism can leverage intercultural competence, resulting in opportunities for deeper cultural insights (Barratt Hacking et al, 2017; Castro et al, 2013; Davy, 


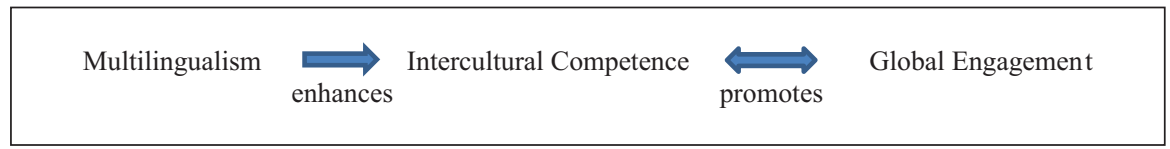

Figure 2. Revised relationship between multilingualism, intercultural competence and global engagement.

2011; Duckworth et al, 2005; Hayden et al, 2000; Muller, 2012; Risager, 2007). In this revised model, multilingualism provides leverage for students who speak different foreign languages. This skill may allow more exposure to different cultural practices and ways of thinking that support the development of their awareness and thereby their global engagement. The study by Metli (2018) showed that as students studied different foreign languages as part of their IBDP Group 1 and 2 (language) courses, they learned about the cultures of the target languages and appreciated different cultural practices, traditions and ways of thinking. Thus, multilingual individuals were able to use the study of foreign languages as a means of gaining intercultural awareness and knowledge. However, intercultural understanding may not be dependent upon being multilingual. As discussed in Barratt Hacking et al (2017), intercultural understanding may also be promoted by other means such as pedagogy, curriculum, and extra-curricular activities. Hence, Figure 2 shows that multilingualism enhances students' intercultural competence, but intercultural competence on its own does not develop students' multilingual abilities because there needs to be deliberate action to develop one's foreign languages. Students who are interculturally competent may also be more informed and aware of the global or cultural issues and therefore act responsibly and so develop their global engagement. Students who are globally engaged in cultural and social issues develop their intercultural sensitivity and understanding, in turn, as they are engaged in reflective practices about how cultures interact in an interconnected world and work collaboratively to resolve global issues. As will be seen in discussion of the other parts of the framework, multilingualism may also play a role in knowledge, skills, dispositions, and agency.

Knowledge, skills, dispositions, and agency. As noted above, both intercultural competence and global engagement are fostered through the development of students' knowledge, skills, dispositions and agency. Identification of these four parts resulted from reflections of the study by Metli, Martin, and Lane (2019) and also through review of the literature. These parts work together to support the learner as a global citizen. Short descriptions of each of these parts are as follows:

- Knowledge (knowledge of sustainability and environmental issues, issues of human rights and social injustice, positive and negative effects of global interdependence, importance and meaning of language, culture and diversity)

- Skills (including taking informed action, critical thinking, communication in different languages, problem-solving, cooperation and conflict resolution, ability to challenge injustices)

- Dispositions (IB learner profile attributes: inquirer, thinker, caring, open-minded, principled, reflective, knowledgeable, communicator, risk-taker, balanced) as described by IB (2008b).

- Agency (including self-efficacy beliefs, confidence, perseverance and commitment, personal goal-setting, self-regulation, intrinsic motivation) as described by Bandura (1977)

The first two parts, knowledge and skills, generally have clear and understood meanings in relation to international mindedness. Among the knowledge and skills is language of course, but there are 
other aspects as well. These include knowledge about different cultures and overall disciplinary knowledge related to the sciences, mathematics, social studies, and so forth. Skills also includes language, but include abilities too such as those described in the IB's Approaches to Learning (thinking, communications, social, self-management and research; IB, 2020c). Perhaps less discussed in the literature related to international mindedness are dispositions and agency. Therefore, more extensive review of the literature related to these parts is included below.

Dispositions. Regarding dispositions, the study by Vooren and Lindsey (2012) indicates that the IB Learner Profile attributes are relevant. Cambridge and Thompson (2004) provide a more critical consideration of dispositions in relation to international mindedness. While they do not use the word "dispositions" in their analysis, many aspects of the definition by Cambridge and Thompson allude to ways of thinking for a globally-minded citizen. They assert that global-mindedness is a "progressive view of education that is concerned with the moral development of the individual by attempting to influence the formation of positive attitudes towards peace, international understanding and responsible world citizenship" ( $p$ 164). They caution that individuals need to examine their own motivations and place in the world. Those in international schools, in particular, need to consider the context of the school; for example, whether it is a part of or isolated from the host country. One context may promote the spirit of collaboration, while the other may offer a more capitalistic view. Therefore, self-reflection and understanding of motivations are important for a global citizen.

Findings of the study by Barratt Hacking et al (2017) also have implications for the label dispositions in the revised framework. For example, they found that participants in the case study schools described IM as ways of thinking, acting, and living, and that IM is a "mind set" ( $p$ 7). Their conclusions regarding the role of language and IM also relate to agency. The authors noted that many participants mentioned the importance of "exploring our own sense of identity, challenging ourselves to grow as individuals, and learning to acknowledge and explore our own assumptions and limitations" ( $\mathrm{p} 8$ ). They stressed the importance of blending IM with local and national mindedness to help students "develop positive self-identity" (p 13). A key finding of the study was that IM involves "reaching out and reaching in", which essentially means that by learning about others, one can gain a greater sense of identity oneself.

Agency. This leads to the role of agency in the revised framework. While Blackmore's (2016) pedagogical framework of global citizenship includes elements of agency through its focus on the aspect of responsible being/action, a further discussion of this concept may be needed to better understand why it is included in the revised framework presented in the current paper. Reeve and Tseng (2011) argue for the inclusion of agency when examining students' engagement. Agentic engagement is in addition to other types of engagement (behavioral, emotional, and cognitive). Reeve and Tseng's thesis relates to how students take charge of their own learning, explaining that "agentic engagement involves students expressing opinions, communicating interests, and asking questions" (p 264). Their study focused on needs satisfaction, noting that there are other facets of agentic engagement ("self-efficacy, personal goals, possible selves, individual interests, and a mastery goal orientation” (p 264). Jackson (2003) provides an argument for the importance of student agency in the learning process. He cites Marzano's (1998) four elements of thought, pointing out that while schools adequately address knowledge and cognition, the elements of metacognition and the self-system need more attention. Through metacognition (planning, goal-setting, self-monitoring, social processing, and help-seeking), students will build their capacity to monitor and become more responsible for their own learning ( $\mathrm{p} 585$ ). To help teachers and administrators to create programs in schools that will better develop students who can become responsible global citizens, Mameli et al (2019) confirmed the importance of 
providing experiences that help students to be "actors and protagonists of their own learning environment" (p 50). These experiences foster student agency, taking self-directed actions to regulate and monitor their own learning.

Social change. There are studies that emphasize how agency and dispositions are related. Deakin Crick and Goldspink (2014) provide an in-depth exploration of theories related to dispositions and engagement. Regarding the latter, they tend to equate it with agency. Their work therefore highlights the importance and inter-dependency of dispositions and agency. They define dispositions by proposing that "how a learner responds to ambiguity and uncertainty at a visceral/emotional level orientates them toward learning in fundamentally different ways" (p 32). They emphasize that attention to students' learning dispositions, in particular their relation to their environment and their teachers, is critical for developing students' involvement in their learning processes. Whether students are passive recipients of knowledge or active generators of knowledge may be affected by myriad aspects of their learning experiences. They explain that:

Learning dispositions are the site for the development of identity and agency precisely because our learning dispositions are uniquely personal yet socially situated, shaping the stories we tell about ourselves as well as framing our future learning trajectories (p 30).

A challenge for curriculum designers, school administrators, teachers, and parents is therefore to provide children with these learning opportunities that both support and challenge them. Within the IB Diploma, the core component of Creativity, Activity, Service (CAS) has the potential to be an ideal venue for students to engage with supportive and challenging experiences for agentic engagement.

Dunne and Edwards (2010) recognize the importance of agency and international mindedness. They studied two international schools in the Philippines in order to explore how these institutions, and their implementation of the IB Diploma, could be agents for social change. Through the interview data collected as part of case study methodology, the researchers gained a variety of insights into how prestigious international schools may help students to become more involved in the local community. Although teachers reported that content related to social justice was included in lessons, the study showed that service learning opportunities and extracurricular projects were instrumental in students becoming involved in the local community. Furthermore, these experiences served to promote teamwork and responsibility, fostered leadership skills, and encouraged students to reflect on their role as change agents. Interestingly, the authors noted that learning English and the local language empowered students, which could contribute to agency. Despite these opportunities, Dunne and Edwards (2010) acknowledge that interactions between the schools and the community were limited, and may even further emphasize the privileges held by the student population. They conclude that though international schools have the capacity to address social injustice, more action and effort is needed to realize this potential.

\section{Conclusion}

In this paper, we present a revised framework that is a development of an empirical study based on Singh and Qi's framework. The study concludes that intercultural competence and global engagement remain important pillars or attributes of IM, but that the role of multilingualism is supportive of, rather than central to, IM. Furthermore, we found that other components were needed to define and explain these attributes of IM. We propose that becoming internationally minded involves an individual expressing all components of the revised framework. Learners as global citizens have 
the knowledge, skills, dispositions and agency to become engaged and competent in understanding, appreciating, and becoming involved in different cultures.

We envision a variety of ways in which this framework could be used by researchers and international schools to design and support comprehensive IM programs. One of the first implications of this framework for international schools may be the need to review and analyse their mission statement. The framework, with its four components, can help school administrators and curriculum planners to ensure that they have a holistic approach to international mindedness. Along these lines, the framework may play a key role in a school's strategic planning. Schools can ensure they have goals that address all four components, especially the often overlooked disposition and agency. The framework may be used as a guide for the development and assessment of international mindedness, especially to make informed decisions about what changes may be needed in learning objectives and curriculum for improvement of practices to promote international mindedness. The components may help with decisions about which instruments to use to collect evidence for monitoring and assessing students' development of international mindedness. Furthermore, the extracurricular activities may be reviewed and enhanced with the help of this revised framework. Programs such as the IB Diploma's Creativity, Activity, Service (CAS) especially have the potential to develop student agency; we recommend that the role of CAS and IM needs further research. At the classroom level, both teachers and students will find ways to apply the framework. Teachers can ensure that they have a variety of activities to address all the components and can also create a rubric to assess the development of students' international mindedness. Students, in turn, may keep a portfolio with personal goals and benchmarks to assess their progress. They can work together with teachers, school staff, and community members to ensure that they are enhancing their knowledge and skills, reflecting on their dispositions, and gaining opportunities to challenge themselves and develop their agency.

The preceding visions provide an initial discussion of how the framework may be used as a tool for developing and assessing IM in terms of cognitive (knowledge), socio-emotional (dispositions and agency) and behavioral (skills) aspects. We present this framework to scholars, researchers, and educators in the field of international education in order to spark further reviews of its design, application, and implications.

\section{Declaration of Conflicting Interests}

The author(s) declared no potential conflicts of interest with respect to the research, authorship, and/or publication of this article.

\section{Funding}

The author(s) received no financial support for the research, authorship, and/or publication of this article.

\section{References}

Bailey K and Harwood R (2013) Evaluating and fostering international mindedness. International School 15(2): 18-20.

Baily S and Holmarsdottir HB (2019) Fostering teachers' global competencies: Bridging utopian expectations for internationalization through exchange. Forum for International Research in Education 5(2): 226-244.

Bandura A (1997) Self-efficacy: The exercise of control. New York: Freeman.

Barratt Hacking E, Blackmore C, Bullock K, Bunnell T, Donnelly M and Martin S (2017) The international mindedness journey: School practices for developing and assessing international mindedness across the IB continuum. Bethesda, MD: International Baccalaureate Organization. Available at: www.ibo.org/ globalassets/publications/ib-research/continuum/international-mindedness-final-report-2017-en.pdf 
Beek A E (2017) Contextual interpretations of international-mindedness in International Baccalaureate Diploma Programme students. Bethesda, MD: International Baccalaureate Organization.

Belal S (2017) Participating in the International Baccalaureate Diploma Programme: Developing international mindedness and engagement with local communities. Journal of Research in International Education 16(1): $18-35$.

Blackmore C (2016) Towards a pedagogical framework for global citizenship education. International Journal of Development Education and Global Learning 8(1): 39-56.

Bunnell T (2019) Developing and institutionalizing the 'Internationally-Minded School': The role of the 'Numerous Fs.' Journal of Research in International Education 18(2): 186-198.

Cambridge J and Thompson J (2004) Internationalism and globalisation as contexts for international education. Compare: A Journal of Comparative and International Education 34(2): 161-175.

Castro P, Lundgren U and Woodin J (2015) International-mindedness through the looking glass: Reflections on a concept. Journal of Research in International Education 14(3): 187-197.

Cause L (2011) International-mindedness: A field of struggle, confusion and hope. Global Journal of Human Social Science 11(7): 35-40.

Deakin Crick R and Goldspink C (2014) Learner dispositions, self-theories and student engagement. British Journal of Educational Studies 62(1): 19-35.

Dunne S and Edwards J (2010) International schools as sites of social change. Journal of Research in International Education 9(1): 24-39.

Fannon O (2013) Growing up in a shrinking world. In L P Stagg (ed), International-mindedness: Global perspectives for learners and educators. London: Urbane Publications, pp. 143-164.

Habib Z (2018) International Mindedness and Intercultural Competence: Perceptions of Pakistani Higher Education Faculty. Journal of Education and Educational Development 5(1): 60-79.

Hammer M, Bennett M J and Wiseman R (2003) Measuring intercultural sensitivity: The intercultural development inventory. International Journal of Intercultural Relations 27(4): 421-443.

Hansen R (2010) Impact of study abroad on ethnocultural empathy and global-mindedness. Muncie, Indiana: Ball State University.

Harwood R and Bailey K (2012) Defining and evaluating international mindedness in a school context. International Schools Journal 31(2): 77-86.

Hayden M C, Rancic B A and Thompson J J (2000) Being international: Student and teacher perceptions from international schools. Oxford Review of Education 26(1): 107-123.

Hayden M and Thompson J (2013) International-mindedness: Connecting concepts to practice. In L P Stagg (ed), International-mindedness: Global perspectives for learners and educators. London: Urbane Publications, pp. 185-204.

Haywood T (2019) Book review: Perspectives on assessment and evaluation in international education by M Hayden and J J Thompson (eds). Journal of Research in International Education 18(1): 90-96.

Hsieh H-F and Shannon S E (2005) Three approaches to qualitative content analysis. Qualitative Health Research 15(9): 1277-1288.

Hill I (2012a) An international model of world-class education: The International Baccalaureate. Prospects 42: 341-359.

Hill I (2012b) Evolution of education for international-mindedness. Journal of Research in International Education 11(3): 245-261.

IB (2008a) IB Learner Profile. Cardiff: International Baccalaureate

IB (2008b) Towards a Continuum of International Education. Cardiff: International Baccalaureate

IB (2020c) Approaches to teaching and learning in the International Baccalaureate Diploma Programme. Retrieved from https://www.ibo.org/globalassets/digital-tookit/flyers-and-artworks/approaches-toteaching-learning-dp-en.pdf

Jackson D B (2003) Education reform as if student agency mattered: Academic microcultures and student identity. Phi Delta Kappan 84(8): 579-585.

Koester J and Lustig M W (2015) Intercultural communication competence: theory, measurement, and application. International Journal of Intercultural Relations 48: 20-21. 
Lindsey R, Roberts L and Campbell Jones F (2005) The culturally proficient school: An implementation guide for school leaders. Thousand Oaks, CA: Corwin Press.

Lineham R (2013) Is the International Baccalaureate Diploma Programme effective at delivering the International Baccalaureate mission statement? Journal of Research in International Education 12(3): 259-282.

Macpherson A (2017) Assessing international-mindedness in staff at an IB PYP school in Erbil (Unpublished Master's thesis). İhsan Doğramacı Bilkent University, Ankara.

Mameli C, Molinari L and Passini S (2019) Agency and responsibility in adolescent students: A challenge for the societies of tomorrow. British Journal of Educational Psychology 89(1): 41-56.

Marshall H (2007) The global education terminology debate: Exploring some of the issues. In M Hayden, J Levy, and J Thompson (eds), The SAGE Handbook of Research in International Education. London: Sage Publications, pp. 38-50.

Mayring P (2014) Qualitative content analysis: Theoretical foundations, basic procedures and software solution. Social Science Open Access Repository. Available at: http://nbn-resolving.de/urn:nbn:de:0168ssoar-395173

Merrill K, Braskamp D and Braskamp L (2012) The global perspective inventory. Journal of College Student Development 53(2): 356-360.

Metli A (2018) Forms of Support and Challenges to Fostering International-mindedness: Perspectives about the International Baccalaureate Diploma Program from Different School Contexts. PhD Thesis, İhsan Doğramacı Bilkent University, Turkey.

Metli A, Martin R A and Lane J F (2019) Forms of support for and challenges to developing internationalmindedness: A comparative case study within a national and an international school in Turkey. Compare: A Journal of Comparative and International Education 49(6): 983-1001.

Morais D and Ogden A (2010) Initial development and validation of the global citizenship scale. Journal of Studies in International Education 15(5): 445-466.

Muller G C (2012) Exploring characteristics of international schools that promote international-mindedness. $\mathrm{PhD}$ Thesis, Columbia University, USA.

Poonoosamy M (2016) Aspirations and tensions in developing international mindedness: Case study of two students in an IB school in an Indian Ocean island nation. Asia Pacific Journal of Education 36(4): 583-598.

Ranger G (2013) International-mindedness at the institutional level in India. In Stagg, L P (ed), International-mindedness: Global Perspectives for learners and educators. London: Urbane Publications, pp. 165-184.

Reeve J and Tseng C M (2011) Agency as a fourth aspect of students' engagement during learning activities. Contemporary Educational Psychology 36(4): 257-267.

Risager K (2007) Language and culture pedagogy: From a national to a transnational paradigm. Clevedon: Multilingual Matters.

Savva M and Stanfield D (2018) International-Mindedness: Deviations, Incongruities and Other Challenges Facing the Concept. Journal of Research in International Education 17(2): 179-193.

Saavedra A R (2014) Academic civic-mindedness and model citizenship in the International Baccalaureate Diploma Program. Bethesda, MD: International Baccalaureate Organization.

Singh M and Qi J (2013) $21^{\text {st }}$ century international-mindedness: An exploratory study of its conceptualization and assessment. The Hague: International Baccalaureate Organization.

Skelton M, Wigford A, Harper P and Reeves G (2002) Beyond foods, festivals and flags. Educational Leadership 60(2): 52-55.

Sriprakash A, Singh M and Qi J (2014) A comparative study of international mindedness in the IB Diploma Programme in Australia, China and India. Bethesda, MD: International Baccalaureate Organization.

Swetz J and Swetz M (2014) How do we know we are internationally minded in a national school? Paper presented at the IB Africa, Europe, Middle East Regional Conference, Rome, Italy, October 2014.

Tamatea L (2008) A practical and reflexive liberal-humanist approach to international mindedness in international schools: Case studies from Malaysia and Brunei. Journal of Research in International Education 7(1): 55-76. 
Tarc P and Beatty L (2012) The emergence of the International Baccalaureate Diploma in Ontario: Diffusion, pilot study and prospective research. Canadian Journal of Education 35(4): 341-375.

Tarc P (2018) "Walking the Talk": A conceptualization of international mindedness to inform leadership in international schools. Peabody Journal of Education 93(5): 486-499.

Vooren C and Lindsey D (2012) Leaders address inequity through a framework of international-mindedness. Journal of Transformative Leadership and Policy Studies 2(1): 25-33.

Wasner V (2016) Critical service learning: A participatory pedagogical approach to global citizenship and international-mindedness. Journal of Research in International Education 15(3): 238-252.

Wells J (2011) International education, values and attitudes: A critical analysis of the International Baccalaureate (IB) Learner Profile. Journal of Research in International Education 10(2): 174-188.

Wright K and Buchanan E (2017) Education for international mindedness: Life history reflections on schooling and the shaping of a cosmopolitan outlook. Current Issues in Comparative Education 20(1): 68-83.

\section{Author biographies}

Akın Metli completed his $\mathrm{PhD}$ with a focus on international-mindedness at Bilkent University, Turkey. Having previously deployed a number of teaching and leadership roles, he currently teaches IB Diploma Theory of Knowledge and is high school principal at Bilkent Erzurum Laboratory School (BELS), as well as being an IB Theory of Knowledge (TOK) examiner, Workshop Leader and School Visit Team Member.

Jennie F. Lane is an Assistant Professor within the Graduate School of Education at İhsan Doğramacı Bilkent University, Turkey. She has experience in curriculum development and teaching secondary school science. Her research areas include environmental, place-based education, and sustainability education. 